\title{
Verzeichnis der benutzten Literatur
}

F. Altheim, Literatur und Gesellschaft im ausgehenden Altertum, Halle 1948

W. A. Baehrens, Rezension der Ausgabe des Ammianus Marcellinus von Ch. U. Clark (Berlin 1910-1915), Bursians Jbb. 1925, 203, 46-90

H. Н. Белова, Социальные движения в Галлии в I-II вв.(N. N. Belowa, Die sozialen Bewegungen in Gallien im 1. und 2. Jahrhundert), Westnik Drewnej Istorii 1952, 4, $45-55^{*}$

E. Bickel, Rezension der Ausgabe des Ammianus Marcellinus von Ch. U. Clark (Berlin 1910-1915), GGA 180, 1918, 274-305

J. Binder, Die Plebs. Studien zur römischen Rechtsgeschichte, Leipzig 1909

R. Cagnat, Cours d'épigraphie latine, Paris 1914

Cambridge Ancient History XII, Cambridge 1939

Cambridge Medieval History I, Cambridge 1911

J. Carcopino, La vie quotidienne à Rome à l'apogée de l'Empire, Paris 1939

Г. Г. Дилигенский, К вопросу об аграрных патроциниях в повдней Римской империи (G. G. Diligenski, Zur Frage der ländlichen Patrozinien im Spätrömischen Reich), WDI 1955, 1, 135-141

Вопросы истории народных движений в поздней Римской Афррике (Fragen der Geschichte der Volksbewegungen im spätrömischen Afrika), WDI 1957, 2, 85-105

А. Д. Дмитрев, Движение latrones как одна из форм классовой борьбы в Римской империи (А. D. Dmitrew, Die Bewegung der latrones als eine der Formen des Klassenkampfes im Römischen Reich), WDI 1951, 4, 61-72

B. Doer, Untersuchungen zur römischen Namengebung, Diss. Berlin 1937

H. Dörries, Das Selbstzeugnis Konstantins, Göttingen 1954

P.-M. Duval, La vie quotidienne en Gaule pendant la paix Romaine, Paris 1952

F. Engels, Der Ursprung der Familie, des Privateigentums und des Staats, Dietz-Verlag Berlin 1953

А. Г. Гемп, Трибутарии и инквилины поздней Римской империи (A. G. Gemp, Die Tributarii und Inquilini der spätrömischen Kaiserzeit), WDI 1954, 4, 75-83

J. W. von Goethe, Italienische Reise, Jubilãumsausgabe Bd. 26-27, Stuttgart-Berlin

R. Günther und G. Schrot, Einige Probleme zur Theorie der auf Sklaverei beruhenden Gesellschaftsordnung, Ztschr. f. Gesch. Wiss. 4, 1956, 990-1008

o. Halecki, Europa, Grenzen und Gliederung seiner Geschichte, Darmstadt 1957

* Im Verlaufe unserer Untersuchung zitieren wir die Namen der sowjetischen Autoren in Umschrift und die Abhandlungen in deutscher Ubersetzung. Westnik Drewnej Istorii im folgenden abgekürzt: WDI. 
L. Harmand, Libanius, Discours sur les patronages, Paris 1955

W. Hartke, Römische Kinderkaiser, Berlin 1951

W. Hoffmann und H. Siber, Plebs, RE XXI, I, 1951, 73-187

Honigmann, Sicarii, RE II A II, 1923, 2461

K. Hönn, Konstantin der Große 2 , Leipzig 1945

P. E. Hübinger, Spätantike und frühes Mittelalter - ein Problem historischer Periodenbildung, Dt. Vierteljahrsschr. f. Lit. Wiss. und Geistesgeschichte 26, 1952, 1-48

A. H. M. Jones, The Roman Colonate, Past and Present Nr. 13, April 1958, 1-13

0. Karlowa, Römische Rechtsgeschichte 2 Bde., Leipzig 1885-1901

S. Katz, The decline of Rome and the rise of Medieval Europe, Ithaca, New York 1955

А. П. Каждан, О некоторых спорных вопросах истории становления феодальных отношений в Римской империи (А. Р. Kashdan, Einige umstrittene Fragen der Entstehungsgeschichte der Feudalbeziehungen im Römischen Reich), WDI 1953, 3, 77-106

E. Kornemann, Weltgeschichte des Mittelmeer-Raumes II, München 1949

А. Р. Корсунский, О положении рабов, вольноотпущенников и колонов в западных провинциях Римской империи в IV-V вв. (А. R. Korsunski, Utber die Lage der Sklaven, Freigelassenen und Kolonen in den westlichen Provinzen des Römischen Reiches im 4. und 5. Jahrhundert), WDI 1954, 2, 47-69

С. И. Ковалев, К вопросу о характере социального переворота III-V вв. в западной Римской имерии (S. I. Kowaljow, Zur Frage des Charakters des sozialen Umschwungs im 3.-5. Jahrhundert im westlichen Römischen Reich), WDI 1954, 3, 33-44

B. Kübler, Geschichte des römischen Rechts, Leipzig-Erlangen 1925

Decurio, RE IV, II, 1901, 2319-2352

В. И. Кузищин, О степени распространения латифундий в Италии в конце республики (W. I. Kusistschin, Utber die Verbreitung der Latifundien in Italien am Ende der Republik), WDI 1957, 1, 64-80

R. Laqueur, Das Kaisertum und die Gesellschaft des Reiches, in: Probleme der Spätantike, Vorträge auf dem 17. Dt. Historikertag, Stuttgart 1930, 1-38

W. Liebenam, Dilectus, RE V, I, 1903, 591-639

Е. Э. Липшиц, Проблема падения рабовладельческого строя и вопрос о начале феодализма в Византии (E. E. Lipschiz, Das Problem des Niedergangs der Sklavenhaltergesellschaft und die Frage der Entstehung des Feudalismus in Byzanz), WDI 1955, 4, $63-71$

K. Marx, Formen, die der kapitalistischen Produktion vorhergehen, Dietz-Verlag Berlin 1952

Lohnarbeit und Kapital, Dietz-Verlag Berlin 1951

Der 18. Brumaire des Louis Napoléon, in: Ausgew. Schriften in 2 Bänden, Berlin 1951

K. Marx und F. Engels, Die deutsche Ideologie, Dietz-Verlag Berlin 1953

N. A. Maschkin, Römische Geschichte, Berlin 1953

S. Mazzarino, Aspetti sociali del quarto secolo, Rom 1951

E. Meyer, Die Sklaverei im Altertum, Kl. Schriften $\mathrm{I}^{2}$, Halle 1924, 169-212

Plebs, in: Handwörterbuch der Staatswissenschaften $6^{3}, 1910,1049-1057$

Th. Mommsen, Staatsrecht I4, Tübingen 1955

R. Paribeni, Da Diocleziano alla caduta dell' impero d'occidente, in : Storia di Roma VIII, Bologna 1942

V. Pârvan, Fouilles d'Histria, Dacia II, 198-248 
A. Piganiol, L'Empire Chrétien, in : Histoire Générale - Histoire Romaine IV 2, Paris 1947

A. Ранович, Колонат в римском законодательстве II-V вв. (A. Ranowitsch, Der Kolonat in der römischen Gesetzgebung vom 2. bis 5. Jahrhundert), WDI 1951, 1, $83-109$

J. S. Reid, The reorganisation of the Empire, in: CMH I, Cambridge 1911, $54 \mathrm{ff}$.

M. Rostowzew, Studien zur Geschichte des römischen Kolonats, Leipzig-Berlin 1910

Gesellschaft und Wirtschaft im Römischen Kaiserreich, übers. von L. Wickert, 2 Bände, Leipzig 1931

A. Graf Schenk von Stauffenberg, Das Imperium und die Völkerwanderung, München 1948

И. В. Шерешевский, Правовое регулирование ,ннаеного труда“ в Риме (I. W. Schereschewski, Die rechtliche Regelung der „Lohnarbeit“ in Rom), WDI 1955, 1, 39-50

G. Schrot - s. R. Günther und G. Schrot

Е. М. Штаерман, Рабство в III-IV вв н. ә. в западных провинциях Римской империи (E. M. Schtajerman, Die Sklaverei im 3. und 4. Jahrhundert in den westlichen Provinzen des Römischen Reiches), WDI 1951, 2, 84-105

К вопросу о крестьянстве в западных провинциях Римской империи (Zur Frage der Bauernschaft in den westlichen Provinzen des Römischen Reiches), WDI 1952, 2, $100-121$

Проблема падения рабовладельческого строя (Das Problem des Niedergangs der Sklavenhalterordnung), WDI 1953, 2, 51-79

Кризис Римской империи (Die Krise des Römischen Reiches), Vortrag, gehalten in Prag im April 1957

Кризис рабовладельческого строя в западньх провинциях Римской империи (Die Krise der Sklavenhalterordnung in den westlichen Provinzen des Römischen Reiches), Moskau 1957

W. Schubart, Justinian und Theodora, München 1943

O. Seeck, Geschichte des Untergangs der antiken Welt Bd. 5-6, Berlin 1913-1920

Colonatus, RE IV, I, 1900, 483-510

M. Seidlmayer, Rom und Romgedanke im Mittelalter, Saeculum 7, 1956, 395-412

H. Siber - s. W. Hoffmann und H. Siber

М. Я. Сюзюмов, Еще раз о юридических источниках для истории колоната (M. J. Sjusjumow, Nochmals die Rechtsquellen für die Geschichte des Kolonats), WDI 1951, 4, $83-88$

К вопросу о процессах феодализации в Римской империи (Zur Frage der Vorgänge der Feudalisierung im Römischen Reich), WDI 1955, 1, 51-67

E. Stein, Geschichte des spätrömischen Reiches I, Vom römischen zum byzantinischen Staat, Wien 1928

K. F. Stroheker, Um die Grenze zwischen Antike und abendländischem Mittelalter, Saeculum 1, 1950, 433-465

Der senatorische Adel im spätantiken Gallien, Tübingen 1948

Das konstantinische Jahrhundert im Lichte der Neuerscheinungen 1940-1951, Saeculum 3, 1952, 654-680

M. Ch. Tissot, Quatrième rapport sur les missions archéologiques en Afrique, Comptes rendus de l'Académie des inscriptions et belles lettres 12, 1885, 64-83

A. Tuilier, Aperçu sur la naissance de la féodalité Byzantine (IV-VI siècles), La Pensée Nr. 66, 1956, 145-151 
3. И. Удальцова, Сельское зависимое население Италии VI века (S. I. Udalzowa, Die abhängige Landbevölkerung Italiens im 6. Jahrhundert), WDI 1955, 3, 85-116

S. L. Uttschenko, Der weltanschaulich-politische Kampf in Rom am Vorabend des Sturzes der Republik, Berlin 1956

W. v. Uxkull, Peculium, RE XIX, I, 1937, 13-16

F. Vittinghoff, Die Bedeutung der Sklaven für den Ubergang von der Antike ins abendländische Mittelalter, Hist. Ztschr. 192, 1961, 2, 265-272

J. Vogt, Konstantin der Große und sein Jahrhundert, München 1949

Sklaverei und Humanität im klassischen Griechentum, Wiesbaden, Abh. d. Akad. d. Wiss. u. d. Lit., geistes- u. soz.wiss. Kl. 1953, Heft 4

F. W. Walbank, The decline of the Roman Empire in the West, London 1946

H. Wallon, Histoire de l'esclavage dans l'antiquité 3 Bde., Paris 1879

B. H. Warmington, The North African Provinces from Diocletian to the Vandal Conquest, Cambridge 1954

L. Wenger, Die Quellen des römischen Rechts, Wien 1953

W. L. Westermann, Sklaverei, RE Suppl. VI, 1935, 894-1068

The slave systems of Greek and Roman antiquity, Philadelphia 1955

P. Winogradow, Social and economic conditions of the Roman Empire in the Fourth Century, CMH I, Cambridge 1911, $56 \mathrm{ff}$.

Ohne Verfasser: Проблема падения рабовладельческого строя (Das Problem des Sturzes der Sklavenhalterordnung), WDI 1956, 1, 3-13 